\title{
On the Origin and History of the English Prepositional Type A-Hunting: A Corpus-Based Study
}

\author{
Paloma Nuñez Pertejo \\ Universidad de Santiago de Compostela
}

\begin{abstract}
The aim of this paper is twofold: in the first place, an analysis on the origin and historical development of the English prepositional phrase a-hunting is provided. According to many scholars, this phrase could be ascribed to a prepositional pattern of the type on + verbal noun in -ing/-ung, apparently in use from OE times. During the ME period, this preposition weakened to $a$ and was finally lost through aphesis, with the result that there were no longer any formal differences between this pattern and the ordinary progressive, while the meaning conveyed by both constructions became practically the same. In the second place, several examples of this prepositional pattern are offered, and for this purpose, the early Modern English section of the computerized Helsinki Corpus has been used, in particular the so-called HE3 section, which covers the period between 1640 and 1710 .
\end{abstract}

\section{Introduction}

The present paper consists of two main sections. The first section is devoted to the origin and historical development of the prepositional type a-hunting. The second section offers statistical data on this pattern in the eModE period, derived from the computerized Helsinki Corpus, which provides samples representing different text-types illustrative of the language of that period. ${ }^{1}$ 
2. Origin and development of the a-hunting type in the history of the English language

There seems to be common agreement in ascribing the origins of the phrase a-hunting in English to a prepositional pattern of the type on + verbal noun in -ing /-ung, which, apparently, was already in use from OE times. Van der Gaaf (202) holds that there is a prepositional construction of the type on hunting ben, which could be traced back to $1 O E$. This pattern occurred side by side with a parallel prepositional structure in which on preceded the verbal noun ending in $-a,-e$ and $-o$ (later $-e t h$ ). Seemingly, both patterns were identical in meaning, but from eME the type with -eth is considered archaic, being thus superseded by the much more common -ing type. Despite the fact that on seems to be the most frequent preposition, in is also common, especially from the late thirteenth century onwards, perhaps due to the influence of the French type en chantant, whereas cases with at have not been recorded. ${ }^{2}$ In this period, the form of the present participle was Vende, which was clearly differenciated from the ending of the verbal noun (-ung/-ing). The prepositional construction was, formally and functionally speaking, very close to the progressive.

During the ME period, the situation is much more complicated, because the traditional ending -ende typical of $\mathrm{OE}$ present participles changed into -ing ${ }^{3}$ and finally coincided with that of the gerund or verbal noun, thus becoming more similar to the construction with which we are familiar today. It also resembled the prepositional construction which occurred in both $\mathrm{OE}$ and $\mathrm{ME}$, be + preposition (often on) + gerund. Whether the progressive directly derives from the OE pattern beon/wesan + Vende or whether it can be ascribed to the prepositional type already found in OE, constitutes one of the most disputed points concerning the history of EFs. The similarities between both patterns can be easily seen, especially because the meaning conveyed by the two of them, the prepositional and the progressive, was practically the same. With the later weakening and disappearance of the preposition, both types were formally identical. The process was, seemingly, the following: before 1200 , unstressed on before a consonant was weakened to $o$ or $a$ (an before a vowel). This an later resulted in $a$, which is the reduced form of the full preposition, a process which has been referred to as aphesis by Jespersen (A Modern English Grammar IV 168-69, 205). With the passage of time, this $a$ completely disappears so that the cluster be + present participle in -ende (later -inge, -ing) becomes formally identical to be + on + gerund.

Two opposing lines of thought summarize the opinions which have come up on this particular topic: there are scholars -Poutsma, Dal, Braaten-who firmly believe that the ME progressive derives from the OE pattern ic woes on huntinge, whereas others - Van der Gaaf, Mossé, Nickel, Scheffer, to mention a few-consider that it constitutes the direct continuation of the OE model beon/wesan + Vende. Despite these contrasted opinions, most linguists seem to agree that the change of the ending of the present participle from -ende to -ing, after it had first changed from -ende to -inge, made it coincide with the nominal form of the verb known as gerund, also ended in -ing. The nominai pattern, with the reduction and later disappearance of the preposition was formally identical to that of be + present participle, the meaning of both constructions being practically the same. 
Jespersen shows a combination of the two above-mentioned theories (A Modern English Grammar IV 168-69): in a first formulation, he asserted that the progressive tenses "seem to have little, if anything, to do with $\mathrm{OE}$ he woes feohtende," and explains the modern forms as the result of a process of aphesis, that is, the preposition on was initially reduced to $a$ and finally disappeared, while the -ing form "is not the participle, but the noun." His view on the matter changed quite drastically after a time and he concluded that modern progressives would then be a combination of the auxiliary verb + present participle in -ende (later -inge, -ing), and the prepositional construction be + on + substantive, "in which on had become $a$ and was then dropped." Jespersen's blending theory has also been supported by Aronstein and Visser, among others. ${ }^{4}$ Visser believes that the coalescence of three different structures complicates the situation in $\mathrm{ME}$. One of the structures he mentions is the prepositional pattern he is on $(a n, a)$ hunting, which can be traced back to an OE pattern of the same type, while it constitutes one of the possible sources in the origin of the ordinary he is hunting progressive.

Celtic influence (Dal, Mustanoja and Braaten) has also been mentioned as a possible source of influence in the origin of this prepositional cluster. According to Dal, OE showed two types of parallel structures, the difference between them being that the participial structures were of a literary nature, while the prepositional ones, i.e. those involving the preposition on and the verbal noun in -ing/-ung, exhibited a more popular character. In $\mathrm{ME}$, the literary progressive was superseded by the popular form in -ing, which was strongly influenced by Celtic. However, our knowledge about the influence of the Celtic gerundial construction in $\mathrm{OE}$ and ME is limited; it is not until the eleventh century that the form ic waes on huntunge is found, and not until the second half of the thirteenth century are to be in doing/to be in building recorded (Scheffer 231).

French influence has also been adduced as a feasible source of influence in $a$-phrases, especially because of the already mentioned effect of the en chantant pattern (cf. Van der Gaaf, Mossé, Braaten), but again, this is difficult to prove, for the data available are far too scarce as to draw any definite conclusions on the subject.

\subsection{Frequency and use}

Although it is true that the a-hunting type represents an interesting type of phrase found in English, most grammarians do not hesitate to point out its infrequent occurrence in each of the periods into which the history of the English language has been traditionally divided. Denison (387), for instance, postulates that this type is not particularly frequent in $\mathrm{OE}$, and that it is also very rare in ME, but for the phrase be on hunting. Ákerlund ("I Go A-Fishing" 13) also states that $a$-phrases were not very common at any point in the history of English; their role being "tributary" rather than constituting "the main stream" of the final pattern (he even refers to these phrases as "ghost-phrases" in his article "A Word on the Passive Definite Tenses" 323). Even Mossé, although he admits their importance and the influence they have exerted on what we may consider true progressives, comments in the fourth chapter of the second part of his extensive 
monograph that their role “a été beaucoup exagéré; si ce tour n'avait pas existé, la FP se serait aussi bien étendue en anglais” ( $\$ 215,127)$.

The period in which they may have enjoyed their greatest popularity is that between $1500-1700,{ }^{5}$ but again, they never represented more than $22 \%$ of the total of progressive forms recorded (Mossé's figures). What did happen was that the true progressive was enriched by the merging of both types, prepositional and prepositionless, its frequency being encreased and its meaning becoming sharply defined and restricted.

The cluster seems to be fairly frequent in colloquial dialectal usage, and although it appeared in literary works of the seventeenth century, it was just occasional and usually retained its colloquial flavour. However, the pattern was far less frequent than ordinary progressive forms. From the eighteenth century onwards it tends to disappear from the language, although there are scholars who think it is still in use in $\mathrm{PE}^{6}{ }^{6}$ but restricted dialectally or regionally, being kept in colloquial speech or when writers tried to give their characters a tone of vulgarity. Writers also used this form to confer an air of antiquity on their work through the speech of older generations: Shakespeare, amongst others, used the prepositional pattern in very colloquial contexts but always much less frequently than ordinary EFs.

\subsection{Function}

Traditional grammars attribute a meaning similar to that of normal progressives to these prepositional patterns, which is the expression of an action in progress. This may be due to the fact that the majority of EFs occur with activity verbs from OE times onwards. Since both patterns, the prepositional and the normal progressive, were then formally identical, they underwent a parallel development. Likewise, as they often fulfilled identical functions, it can be said that the $a$-hunting type influenced the progressive very strongly, especially in restricting its function to the expression of an action in progress. Despite this being the general opinion, Akerlund ("I Go A-Fishing" 11) suggests that there are certain types of $a$-phrases which show some kind of peculiarity, especially cases such as go $a$ fishing and be a-hunting, which may be not easily seized: the a-cluster expresses or suggests some intention; someone has gone out with the intention of hunting or fishing something. This intentional meaning seems not to be present in the normal he is hunting progressive.

Jespersen (Essentials of English Grammar 263) considers that the meaning usually associated with the normal progressive (that of serving "as a frame round something else") originated in the old prepositional phrase he was on hunting, which meant he was in the course of hunting, engaged with hunting. ${ }^{7}$ In other words, $a$-phrases contributed in some way or other to consolidating the current meanings normally related to modern progressives.

Elsness (12) believes that the meaning of these constructions did not essentially differ from that of the modern progressive; on the contrary, they are clearly related to PE progressives and are very often treated as early instances of these verb forms. This similarity is less apparent in those cases in which the preposition appears in its complete 
form, i.e. cases with upon. According to this scholar, ModE progressives clearly deviate, formally and syntactically, from both OE patterns, prepositional and prepositionless, which is why their frequency is explained in terms of the merging of both constructions, the prepositional pattern contributing "to the meaning of the progressive as it functions in the present-day language" (22).

There is another peculiarity which seems to be present in this prepositional pattern: in certain contexts a passive meaning could be associated to the cluster, especially when the underlying object appeared as subject of the sentence as in the house is in building. Denison (392) finds that patterns of this kind, i.e. the house is on/in/a building, could be "even more crucial to the passival than the prepositional patterns [of the type he is on hunting] were to other progressives." It has been generally agreed that the OE construction consisting of a preposition and a gerundial verb, of the type ic was on huntun $e$, under certain circumstances, lends itself better to the expression of passive meaning.

Summing up, it can be said that $a$-phrases were formally and syntactically similar to constructions showing be + present participle. Moreover, this similarity could even be extended to the meaning and function conveyed by both patterns. In semantic terms, $a$ phrases and ordinary progressives seemed to be very close, but for the fact that $a$-phrases, in addition, were sometimes capable of expressing intentionality (cf. Åkerlund "I Go AFishing"), something which was not overtly present in normal progressives. We have also seen that prepositional phrases, in certain contexts and under certain circumstances, were capable of conveying passive meaning, both through the full and reduced form of the preposition: the house is in building and the house is abuilding. However, modern progressives can be explained in terms of the merging of both prepositional and prepositionless patterns, rather than attributing their origin to just one of the two constructions. In this sense, I completely coincide with Elsness, for I really hesitate whether ModE expanded forms are simply a direct continuation of OE beon/wesan + Vende. It seems more likely that the prepositional pattern, once the preposition had disappeared and the resulting pattern was therefore identical to that of $b e+$ present participle, merged with the prepositionless construction. From that blending, true progressives developed in $\mathrm{eModE} .^{8}$ The truth is that with the merging of both forms, the frequency of the progressive increased and the function it fulfilled and the meaning it conveyed sharpened once it had replaced the prepositional pattern.

As for the verbs which usually precede $a$-phrases, it should be noted that $b e$ is not the most frequent one. Verbs of motion, which express the result or purpose of the action ("activity verbs" in Nehls' terminology), and verbs such as go, ride, lie, see, find, etc., are more common, alongside verbs such as set, which express some kind of ingressive meaning. Van der Gaaf (208) suggests that there has always been a marked preference for the use of the progressive with verbs of rest and motion, go and come being the most frequent, while verbs such as live or $d w e l l$ are also used, for they illustrate the continuity of the action conveyed by the progressive tenses very suitably. 


\subsection{Disappearance}

On the one hand, Åkerlund ("I Go A-Fishing") believes that the disappearance of these phrases may have been due to the arrival of people coming from the North of England (Northeners), for this special type of cluster did not occur in their dialect, along with the fact that, in the south of the country, $a$-phrases had to compete with expressions showing no preposition at all, which were far more frequent. Both facts contributed to the final disappearance of the pattern.

Scheffer, on the other hand, considers that the loss of the prefix in participles took place quite early, at about the end of the thirteenth century, while those prefixes that remained in the language were simply used to confer a rustic or archaic flavour on a turn of speech. The reason he adduced for the early loss of the $a$-prefix was the influence of Latin "in the language of scholars and the educated, whereas it was retained in the language of the people" (246). ${ }^{9}$ Bergeder, however, states that it is from the eighteenth century onwards that these forms tend to disappear from the language, although some of them may have survived in some regions, especially in southern dialects and also in vulgar speech, both in England and America.

\section{The a-hunting type in early modern English: Data from the Helsinki Corpus}

Although the eModE section of the Helsinki Corpus comprises three main subperiods, 1500-1570 (HE1), 1570-1640 (HE2) and 1640-1710 (HE3), I will offer statistical data only from the last subperiod, which contains more examples of $a$-phrases than the other two.

Table 1 illustrates the total number of words investigated in this subperiod, together with the number of ordinary progressive constructions found in it. The number of $a$ phrases which occur in this subperiod is also included ${ }^{10}$ as well as their relative frequency with respect to ordinary progressives, as the percentage on the right shows:

\begin{tabular}{|c||c|c|c|c|}
\hline TABLE 1 & WORDS & ORDINARY PROGRESSIVES & A-PHRASES & $\%$ \\
\hline HE3 & 171040 & 93 & 12 & 12,9 \\
$1640-$ & & & & \\
1710 & & & & \\
\hline
\end{tabular}

As regards ordinary progressive constructions, I have adopted a "restrictive" definition of the concept and I have included those cases which can be considered straightforward instances of the progressive. Thus, be going to + infinitive patterns and covert passives, i.e. active progressives capable of passive meaning, of the type the house is building, have been excluded from the classification.

As we can see from Table 1, the number of $a$-phrases is not high, even in the period in which they were most frequent, i.e. the eModE period. Despite the fact that their number increases slightly from HE1 to HE3, they never surpass the frequency of normal 
progressives. Moreover, in terms of relative frequency of occurrence, the use of $a$-patterns decreases considerably because of the more frequent appearance of ordinary progressive constructions. However, the role of $a$-phrases in the eModE period seems to have been decisive, because the increase in use of the progressive is difficult to account for, except as a result of the blending of both constructions: the prepositional and the prepositionless.

Table 2 provides the classification of the text types examined and the number of $a$ phrases found in them. As the pattern seems to be more frequent in colloquial and dialectal usage, its occurrence would be expected in oral texts, such as dramas, comedies and so on, rather than in formal, educated written texts:

\begin{tabular}{|c|c|c|c|c|c|c|}
\hline TABLE 2 & Handb. & $\begin{array}{c}\text { Proceed., } \\
\text { trials }\end{array}$ & Autob. & Fict. & $\begin{array}{c}\text { Drama, } \\
\text { comed. }\end{array}$ & Lett. \\
\hline $\begin{array}{c}\text { HE3 } \\
1640-1710\end{array}$ & 1 & 1 & 1 & 3 & 4 & 2 \\
\hline
\end{tabular}

As can be seen in Table 2, it is therefore not surprising to observe that it is this type of text (dramas, comedies) that contains more examples of $a$-phrases, closely followed by fictional texts and letters. Other types of texts, such as handbooks or trials, apparently fulfil the prerequisite of being speech-based, too. This prerequisite, however, seems not to be completely satisfied in one example, representative of the autobiographical genre. As a general rule, autobiographies are supposed to be written works in which people narrate or describe events and experiences of their own lives. In that sense, a formal register could be expected and an educated author assumed. Nevertheless, the language in this type of text at this time seems to be very close to the spoken language, as the writers merely narrate things as they happen, as if they were recounting stories in front of an imaginary audience. Moreover, the style exhibited in this type of prose is not very elevated, in contrast with the much more formal, artificial style of, for instance, statutes, sermons and philosophical works.

That $a$-phrases tend to occur in dialectal and colloquial speech is something which most scholars seem to agree on. In this sense, Leah Dennis, when referring to the frequency of progressive tenses in English, includes what he denominates "mid-forms", of the type a-saying, whenever they appear, "usually in the lips of servants" (858). This assertion could even be extrapolated to the progressive forms in general, for their use "is much more frequent in colloquial than in formal language" (858).

Table 3 reflects the type of verbs that precede the $a$-phrase. I have already put forward that be was not the usual verb found before these phrases, the $a$-pattern being generally attested after verbs of movement. However, and as Table 3 shows, most of the examples recorded are preceded by a form of to be; in such cases, the $a$-phrase is felt to be much closer to the ordinary progressive. The remaining examples display verbs other than be (find, go, set, fall, have, etc). Since it is difficult to speak of real progressives in these 
cases, the -ing forms following verbs other than be should better be referred to as appositive participles: ${ }^{11}$

\begin{tabular}{|c|c|c|}
\hline TABLE 3 & TO BE & OTHERS \\
\hline \hline VERBS & 7 & 5 \\
\hline
\end{tabular}

Some of these verbs, however, are found in combinations which imply "being" of some kind:

(1) It's well I have a Husband a coming, or Icod, I'd marry the Baker, I wou'd so. (HE3, John Vanbrugh, The Relapse, PI, 61).

So far, we have been dealing with $a$-phrases solely, whereas no mention of complete prepositions has been made. To the best of our knowledge, there is just one case in which the full form of the preposition is attested, the meaning of which clearly resembles the ordinary progressive:

(2) Dr Bargrave is newly chosen Prebend of Cantebury in roome of an old Prebend lately deceased and is now uppon going to Argiers to redeem some Captives (HE3, September 1662, Henry Oxinden, Letter to his wife, 275).

According to Elsness (13) "the similariry with the present-day progressive construction is less striking in cases where the preposition appears in its full form." In contrast with those cases in which the preposition appears in its complete form, the examples showing the prepositional remnant $a$ are more likely to be associated with normal progressives. Nevertheless, the example above with uppon has a lot in common with a PE progressive, and could well be treated as an early instance of this verb form.

Another feature which all these constructions seem to have in common is the intransitive character of the verb inside the $a$-phrase. The prepositional patterns recorded -both with preposition or the prepositional remnant- do not take an object, except for one instance in which a direct object follows the prepositional phrase a visiting:

(3) Mrs. (Harwell). One Madame (Dormer) was then in those Parts, and being gone a visiting his friends at (Black-Ladies), I writ to him, and desired him to give her a Visit, for I knew she would be glad to see him (HE3, The Trial of Titus Oates, p. IV, 82.C1). ${ }^{12}$

The intransitive character of the verbs inside these phrases has been felt as an evidence of the gerundial nature of the -ing form. Although it is true that gerunds show some kind of verbal status and therefore may take objects, "such objects are less likely in constructions of the original prepositional type," i.e. of the type ic was on huntun $e$ (Elsness 22).

The type of clause - main or subordinate - in which $a$-phrases are found can be seen in Table 4: 


\begin{tabular}{|c|c|c|}
\hline TABLE 4 & MAIN & SUBORDINATE \\
\hline TYPE OF CLAUSE & 4 & 8 \\
\hline
\end{tabular}

As Table 4 shows, $a$-phrases seem to be more frequent in subordinate clauses, ${ }^{13}$ especially in those clauses which denote some kind of temporal reference:

(4) This gave him some chagreen; however, it gave him also the opportunity one day, when the prince was a hunting, to wait on a man of quality, as his slave and attendant, who should go and make a present to (Imoinda), as from the prince; ... (HE3, Aphra Behn, Oroonoko, 157-158).

The action denoted by the $a$-phrase here constitutes a temporal frame for the whole situation. In this sense, the meaning conveyed by the $a$-phrase would be very close to that of a normal progressive, for the EFs "therefore call the attention more specially to time," in contrast with the simple forms, "which speak of nothing but the action or state itself" (Jespersen, A Modern English Grammar IV 180). The evidence shown by Table 4 seems to be in connection with the diachronic line traced from the use of the progressive "as a framing device, often found in subordinate clauses introduced by adverbs such as while, as; ..., to its foregrounding function in main clauses in the nineteenth century novel" (Wright 468). Strang's assertion seems to confirm this when she says that "in narrative prose of the first half of the eighteenth century the construction is truly at home only in certain types of subordinate clause, especially temporal, relative or local ... In other types of subordination, in co-ordination and in independent main clause use it is rare, though like most things in language, not impossible" (441).

Maybe an additional meaning of intention (cf. Åkerlund "I Go A-Fishing") could be noticed in some of the examples recorded. This meaning is perhaps not easily seizable or analysed, but maybe a difference between he is hunting and he is a-hunting can be felt: he is a-hunting expresses an intention (he has gone out in order to hunt) which seems not to be present in the he is hunting pattern.

In the same way that the kinds of adverbial which appear in ordinary progressive constructions influence their use and meaning, adverbial specification is also present in $a$ phrases, although it seems not to be very common, as Table 5 shows:

\begin{tabular}{|c|c|c|}
\hline TABLE 5 & ADVERB & $\varnothing$ \\
\hline \hline ADVERBIAL SPECIFICATION & 3 & 9 \\
\hline
\end{tabular}

Very often, the adverbials recorded express frequency or length of time:

(5) (Miss.) No more we shan't indeed, for he loves her better than he loves his Pulpit, and wou'd always be a preaching to her, by his good will (HE3, John Vanbrugh, The Relapse, PI, 62). 
Apparently, adverbials such as ever, always, all day, etc., were very often used with the progressive tenses, especially in ME. However, in PE, the combination of some of these adverbials with the progressive sometimes gave an emotional colouring to the expression, usually by conveying annoyance or irritation, as in you are always telling lies. A similar reading might be assigned to (5), although it may be not so clear whether always denotes annoyance or simple repetition.

Now is very often understood when the present tense of the EF is used, but it is also explicitly mentioned to show the connection of the action or state with the time of speaking:

(6) Dr. Bargrave is newly chosen Prebend of Canterbury in roome of an old Prebend lately deceased and is now uppon going to Argiers to redeem some Captives (HE3, September 1662, Henry Oxinden, Letter to his wife, 275).

The fact that early constructions such as (5) and (6) showed adverbial specification lead us to conclude that the use of these adverbials in $a$-phrases was very similar to their use in EFs. Likewise, the similarity between EFs and prepositional phrases has also been shown under different parameters. Thus, constraints such as the more frequent occurrence of $a$-phrases in colloquial, speech-based texts, in subordinate rather than in main clauses as well as the adverbial specification exhibited, can also be applied to progressives in general, at least at earlier stages of language. However, the gerundial status associated with -ing forms in prepositional patterns may account for the fact that $a$-phrases, as a general rule, did not take direct objects, in contrast with ordinary EFs. All this can be felt as an evidence that, in eModE, both constructions were still separate, for the difference between their respective historical origins could still be appreciated. Nevertheless, the merging of both patterns in the IModE period contributes to the sudden increase in use of the construction, although its frequency goes on doubling in subsequent centuries (cf. Strang).

\section{Conclusion}

Despite not representing a very common feature in any of the periods of the history of the English language, $a$-phrases constitute an interesting example of English verbal syntax. Even though their number increases during the eModE period, from HE1 to HE3, their relative frequency of occurrence decreases because of the more frequent use of ordinary progressives. The merging of both constructions -the prepositional and the prepositionless - may, perhaps, account for the sudden increase in use of the progressive from the eModE period onwards and, for many reasons, it seems obvious that the prepositional construction has contributed to the settlement of PE progressive meaning. Thus, the importance of the prepositional pattern should not be measured in terms of its frequency, for this has always been much lower than that of EFs, but it should be viewed in the light of its contribution to the development of the final -ing pattern and also to the increasing use of the periphrasis even from lME onwards.

1500-1700 undertakes the period in which these phrases apparently enjoyed their greatest popularity, especially in colloquial dialectal usage. According to their level of 
style, writers of that period would make more or less use of the form, depending on the colloquial tone they wished to confer on their work. Thus, John Evelyn does not use $a$ phrases at all in the fairly elevated style of his Diary, in contrast with the much more colloquial writing of Samuel Pepys. A-phrases are also frequent in the Hatton Correspondence, something which our analysis of data has proved true, since three of the examples recorded, if we include the example with uppon, have been found in private letters. The investigation carried out in the Helsinki Corpus seems to confirm the association of $a$-phrases with colloquial levels of style, in contrast with mannered styles of writing, such as statutes, sermons, science treatises and so on, which are likely to avoid them.

From the eighteenth century onwards these forms tend to disappear from the language and are only retained colloquially. Dickens, among other writers, makes use of these forms when he wants his characters sound vulgar, as they are typical of people from the lower classes. According to many scholars, $a$-phrases are still alive in both dialectal $\mathrm{BrE}$ and AmE, although the pattern still maintains its colloquial ring, and is avoided in literary diction. However, many a-phrases seem to be obsolete nowadays, but for some combinations which are said colloquially: keep the pot a-boiling, set a-rolling, as well as a few expressions which keep the full preposition: be in hiding, be long in coming, etc. Although it has generally been acknowledged that the realm of the $a$-phrase seems to be the southern dialects of England and North-America, the pattern being always associated with colloquial levels of language, more investigation into the usage of the a-hunting construction should be carried out, especially in the domain of British and American dialects.

\section{Notes}

1. The abbreviations used in this paper are the following: $\mathrm{OE}=\mathrm{Old}$ English, $\mathrm{OOE}=\mathrm{late}$ Old English, eME=early Middle English, ME=Middle English, IME=late Middle English, eModE=early Modern English, ModE=Modern English, lModE=late Modern English, PE=PresentDay English, BrE=British English, AmE=American English and EF=Expanded Form.

2. No examples with at have been recorded in OE, but it is sometimes used in ME. However, the most widespread preposition in ME seems to be in, not on.

3. The evolution from -ende to -ing is due to several phonological changes produced, basically, by the interchange of the consonantic groups $-n d,-n g$ and $-n$. The fact that -ing(e) finally replaced end $(e)$ is motivated by the influence of the verbal noun, also ended in in -ing $(e)$ from the thirteenth century onwards. At the beginning of the fourteenth century, the ending -ing began to spread from the South to the rest of the country and, in a relatively short period of time, it became the usual ending of the present participle, and also of the gerund or verbal noun, thus replacing the traditional -ung typical of verbal nouns.

4. Modern theories, however, seem to put a special emphasis on the continuity of the progressive from $\mathrm{OE}$ to $\mathrm{PE}$.

5. 1500-1700 covers the period traditionally denominated eModE, on which the second part of this paper is based. 
6. Combinations with $a$ - are still found in Scotland and in the southern Midlands, most of them, however, dialectically restricted.

7. The meaning is that the hunting had already begun and was not completed at the time mentioned or implied in the sentence, but it may be completed now (we don't really know).

8. We should be aware of the fact that the progressive forms we are familiar with today are not completely identical to those forms found in eModE, since from lModE times onwards, these verbal constructions still underwent changes before reaching their present form.

9. However, this scholar admits that the $a$-prefix is still kept "in the popular tunes of the thirties ': I'm a-sittin' and a-rockin" ", and also in "the world of rustic speech, ..., or, with archaic overtones" (103).

10. The number of $a$-phrases found is slightly higher than the number of cases recorded by Elsness in the same period and in the same corpus. The reason for this difference is that verb phrases other than be-phrases have been included, although they are far from being classified as real EFs.

11. In fact, these so-called appositive participles resemble OE constructions of the type he sat laerende, i.e. first or present participles with verbs of state or motion, which cannot be classified as EFs.

12. Elsness (22), however, points out that "not a single prepositional progressive was recorded taking an object," although his classification is more restrictive than ours, for he, as we have already mentioned, does only include be-phrases, while the example above involves go $+a$ phrase.

13. In OE, however, the progressive is found proportionately more often in main clauses than in subordinate clauses, and this is even more frequent when the progressive is specified by temporal adverbials (Scheffer $182 \mathrm{ff}$.).

\section{Works Cited}

Åkerlund, A. “A Word on the Passive Definite Tenses." Englische Studien 47 (1914): 321-37. . "I Go A-Fishing: An Historical and Geographical Sketch of the A-Phrase in its Active Significance." Studia Neophilologica 9 (1936): 3-13.

Aronstein, P. “Die Periphrastische Form im Englischen.” Anglia 42 (1918): 1-84.

Bergeder, F. Die Periphrastische Form des Englischen Verbums im 17. Jahrhundert. Halle, 1914. Braaten, B. "Notes on Continuous Tenses in English." Norsk Tidsskrift for Sprogvidenskap 21 (1967): 167-80.

Dal, Ingerid. "Zur Entstehung des Englischen Participium Praesentis auf -ing." Norsk Tidsskrift for Sprogvidenskap 16 (1952): 5-116.

Denison, David. English Historical Syntax. New York: Longman, 1993.

Dennis, Leah. “The Progressive Tense: Frequency of its Use in English." Publications of the Modern Language Association of America 55 (1940): 855-65.

Elsness, Johan. "On the Progression of the Progressive in early Modern English." ICAME 18 (1994): 5-25.

Jespersen, Otto. A Modern English Grammar on Historical Principles. London: Allen and Unwin, 1909-1949.

. Essentials of English Grammar. London: Allen and Unwin, 1933.

Mossé, Fernand. Histoire de la Forme Périphrastique Être + Participe Présent en Germanique 1 \& 2. Paris: C. Klincksieck, 1938. 
Mustanoja, Tauno F. A Middle English Syntax. Helsinki: Société Neophilologique, 1960.

Nehls, Dietrich. "On the Development of the Grammatical Category of Verbal Aspect in English." Essays on the English Language and Applied Linguistics on the Occasion of Gerhard Nickel's 60th Birthday. Eds. J. Klegraf and D. Nehls. Heildeberg: Groos, 1988. 173-98.

Nickel, Gerhart. Die Expanded Form im Altenglischen. Neumünster: Wachholtz, 1966.

Poutsma, H. A Grammar of Late Modern English. Groningen: Noorhoff, 1926.

Scheffer, Johannes. The Progressive in English. Amsterdam: North-Holland, 1975.

Strang, Barbara M.H. "Some Aspects of the History of the Be + Ing Construction." Language Form and Linguistic Variation. Papers Dedicated to Angus McIntosh. Ed. J. Anderson. Amsterdam: Benjamins, 1982. 427-74.

Van der Gaaf, W. "Some Notes on the History of the Progressive Form." Neophilologica 15 (1930): 201-15.

Visser, Frederic Theodor. An Historical Syntax of the English Language. Leiden: Brill, 1963-73. Wright, Susan. The Mystery of the Modal Progressive." Studies in Early Modern English. Ed. D. Kastovsky. Berlin/New York: Mouton de Gruyter, 1994. 467-85. 